\title{
Factors Responsible for Violent Behaviours among Secondary School Students as Expressed by Teachers in Ilorin Metropolis, Kwara State
}

\author{
Olushola A. Iyekolo, Ifeoma P. Okafor and Isiaka Abdulaziz
}

\begin{abstract}
This study investigated the factors responsible for violent behaviours among secondary school students as expressed by teachers in Ilorin Metropolis, Kwara State. The population for this study comprised all teachers in Ilorin metropolis. A researcher-designed questionnaire was designed to gather data from the respondents. The validity and reliability of the instrument were established. The data collected were analyzed using both descriptive and inferential statistics. For the demographic data, percentages were employed while t-test statistical tools were employed to analyze the hypotheses at a 0.05 level of significance. Findings revealed that the factors responsible for violent behaviours are extreme annoyance displayed by parents towards their children, extreme harshness towards children by parents, and inconsistent parental responses to children's needs among others. There were no significant differences in the factors responsible for violent behaviours among secondary school students as expressed by teachers in Ilorin metropolis based on gender and years in teaching. It was recommended that counselling centres should be established and made functional in all secondary schools in Ilorin and Nigeria in general.
\end{abstract}

Keyword: violent behaviour, students, teachers, Ilorin

Olushola A. Iyekolo, Ph.D., a Lecturer in the Department of Social Sciences Education, University of Ilorin, Nigeria obtained her Doctor of Philosophy (Ph.D.) (2013) in Sociology of Education from the University of Ilorin, Nigeria. Iyekolo is a registered teacher with the Teachers' Registration Council of Nigeria (TRCN). She is a member, Association of Sociologists of Education in Nigeria, and Member, Social Studies Association of Nigeria. Recent publications include: Iyekolo, A. O. (2020): Non-verbal communication and management of interactive conflicts in school-based violence: A sociological perspective. Canadian Journal of Family and Youth, 12(1), 260-268; Iyekolo, A. O., Okafor, I. P. \& Abdulaziz, I. (2020). Attitude of teachers towards women leadership of secondary schools in Ilorin, 
Kwara State. Anatolian Journal of Education, 5(1), 135-140. (A Journal of the Faculty of Education, Eskisehir Osmangazi University, Turkey). Available online at http://e-aje.net/images/dosyalar/aje_2020_1_13.pdf

Ifeoma P. Okafor, Ph.D., a Lecturer in the Department of Social Sciences Education, University of Ilorin, Nigeria obtained her Doctor of Philosophy (Ph.D.) (2013) in Sociology of Education from the University of Ilorin, Nigeria. Okafor is a registered teacher with the Teachers' Registration Council of Nigeria (TRCN). She is a member, Association of Sociologists of Education in Nigeria, member, Social Studies Association of Nigeria, and Member, History of Education Society of Nigeria. Recent publications include: Okafor, I. P. (2020). Causes and consequences of drug abuse among youth in Kwara State, Nigeria. Canadian Journal of Family and Youth, 12(1), 147-162. (A Journal of the University of Alberta). Available online at http://ejournals,library,ualberta.ca/index/php/cjfy; Okafor, I. P. (2020). Influence of domestic violence on girl-child academic performance of students in Itesiwaju Local Government Area, Oyo State, Nigeria. Anatolian Journal of Education, 5(1), 119-124. (A Journal of the Faculty of Education, Eskisehir Osmangazi University, Turkey). Available online at http://eaje.net/images/dosyalar/aje_2020_1_11.pdf; Iyekolo, A. O., Okafor, I. P. \& Abdulaziz, I. (2020). Attitude of teachers towards women leadership of secondary schools in Ilorin, Kwara State. Anatolian Journal of Education, 5(1), 135-140. (A Journal of the Faculty of Education, Eskisehir Osmangazi University, Turkey). Available online at http://e-aje.net/images/dosyalar/aje 2020 1 13.pdf

Isiaka Abdulaziz, Ph.D., a Lecturer in the Department of Social Sciences Education, University of Ilorin, Nigeria obtained his Doctor of Philosophy (Ph.D.) (2014) in Sociology of Education from the University of Ilorin, Nigeria. Abdulaziz is a registered teacher with the Teachers' Registration Council of Nigeria (TRCN). He is a member, Association of Sociologists of Education in Nigeria. Recent publications include: Iyekolo, A. O., Okafor, I. P. \& Abdulaziz, I. (2020). Attitude of teachers towards women leadership of secondary schools in Ilorin, Kwara State. Anatolian Journal of Education, 5(1), 135-140. (A Journal of the Faculty of Education, Eskisehir Osmangazi University, Turkey). Available online at http://e-aje.net/images/dosyalar/aje_2020_1_13.pdf 


\section{Introduction}

Violent behavior is not a new phenomenon in the contemporary educational system. It is manifested in the form of rioting, sexual violence, fighting and bullying. These destructive activities contribute to physical disabilities, drop out and poor academic performance among students.

Violence in secondary schools is not a new problem. It occurs between two or more individuals as interpersonal violence, or it involves identifiable groups in the society and erupts as intergroup violence between two or more different religions or ethnic groups. For centuries, violence has been a commonplace feature of school life with its causes embedded in the social, cultural, historical and economic contexts of its time (Leach \& Zekpe, 2010). The focus of violence can be individuals, objects or the school itself, and the nature of the damage can be psychological, physical or material. Since the middle of the 20th century, violence against children has increasingly been viewed as a violation of their fundamental human rights, in particular of their right to physical safety and psychological security and wellbeing (Rukundo, Kibanja \& Steffens, 2017). In addition, there has been recognition that either schools can help to prevent violence against children or that they create an environment that reinforces violent attitudes. Violence is a disturbing issue across the world today. It is a subject of great concern in homes, schools, work places, and social places, rural and urban areas.

According to Rutebuka (2001), violence is an unjust force or injury that is done to that which is entitled to respect or observance. Violence is evident in educational, social, family and political scenarios as observed by various authors. For example, Severe (2000) argued that violence has become rampant in society for the simple reason that when children are exposed to so many acts of violence (even through the media), they begin to believe that violence is acceptable. School violence is equally a central issue of concern for school personnel, researchers and families. English (2004) emphasized that research has shown that violence and misbehavior, negatively impact on the learning environment, and promote a climate and a culture of concern and fear among teachers and administrators while at school. Furthermore, violence disrupts schools from functioning, students from learning and teachers from working. It is clear from the above explanations that violence is deeply rooted in our contemporary society. However, this should not scare us from seeking solutions that can help to eradicate the problem of violence.

According to Alcorn et al.., (2000), school administration plays a critical role in discipline. Whenever a head teacher fails to give teachers the help they deserve in disciplining students, control problems multiply and school morale deteriorates rapidly. It is noted that policies and regulations that govern achievement and behaviour of its students are also a source of disciplinary problems arising within the school. In this case, regulations, as well as their enforcement, which are either too severe or too lax may also lead to control problems. Administrators, who frequently resort to physical punishment, especially for the older children, soon reap a harvest of rebellion and aggressive behaviour. Disorder results due to bureaucracy in schools, which is seen in rigid uniformity and rigid expectations.

The reasoning in this case is that head teachers are not considerate of exceptional children. It is noted that highly bureaucratic schools allow little responsibility and do not empower students to learn on their own (Macionis, 2007). The head teacher's communication 
style is a process of transferring thoughts, feelings or information from one person to another. It is an area that a school head teacher should handle cautiously. Communication is either verbal or non-verbal. The school's verbal communication may include announcements, classroom teaching, commands and directives by word of mouth. On the other hand, non-verbal communication may involve tone of voice, postures, crying, slamming a door, nodding, or shaking a head, clapping hands and frowning. Of interest, however, is the fact that non-verbal communications are indications of motives, feelings and sentiments. Despite many strategies put in places to curb it, the problem persists. School is perceived to be a place where students should feel safe and secure but the opposite is the case. The reality is that a significant number of students are the target of the bullying. Bullying though old, is a widespread and worldwide problem. Most adults can remember incidents like bullying in which they were either bullies or bullied. In fact, until recently, the common perception had been that bullying was a relatively harmless experience that many children experience during their school years.

However, over the past two decades, an extensive body of research has documented that bullying is a potentially damaging form of violence among children and youth. So, while bullying is not a new phenomenon, what is new is the growing awareness that bullying has serious damaging effects for bullies, victims, schools and communities. Consequently, concerns of parents, policymakers, educators and the public have escalated in countries around the world with the rise in the reported incidents of violence and the links that have been established between violence and bullying. In the western world, much attention has been devoted to stemming the act of bullying but in Nigeria this act goes on in many schools unnoticed. Bullying has been defined variously by researchers. According to Nations Team (2007), bullying occurs when a person willfully and repeatedly exercises power over another with hostile or malicious intent. A wide range of physical or verbal behaviours of an aggressive or antisocial nature are encompassed by the term bully. These include "insulting, teasing, abusing verbally and physically, threatening, humiliating, harassing and mobbing" (Colvin et al., 2008). Bullying may also assume a less direct form (sometimes known as "psychological bullying") such as gossiping, spreading rumours, and shunning or exclusion (Nations Team, 2007).

A broad definition of bullying as opined by Leach and Zekpe (2010) is when a student is repeatedly exposed to negative actions on the part of one or more other students. These physical actions can take the forms of physical contact, verbal abuse or making faces and rude gestures. Spreading rumours and excluding the victim from a group are also common forms of bullying. These negative actions are not necessarily provoked by the victim for such action to be regarded as bullying; an imbalance in real or perceived power must exist between the victim and the person who victimizes him or her (Cheurprakobkit \& Barstch, 2005). According to Schuster (1996), this power of imbalance and the fact that bullying behaviours are repeated over time are what differentiate bullying from other forms of aggressive behaviour. Pepler and Craig (2000) observed that bullying is the most common form of violence. It is what drives the culture of violence, permitting the most powerful to dominate the less powerful ones. Violence implies a physical attack of an individual on another person. Activities that may legally involved violence include hunting, law enforcement, sports and war. Crime includes many illegal forms of violence 
such as armed robbery, burglary, arson suicide, rape, thuggery, murder, illegal forms of firearms and illegal forms of violence that hates to be recognized in the rules and regulations of a given society.

Webster's dictionary of English language defines 'violence' as the quality or state of being violent, intensity fury, also unjust exercise of power, injury, outrage, physical force unlawfully exercised and act tending: an act tending to intimidate or overawe by causing apprehension of bodily injury. Violence is not just physical. People inflict psychological and emotional damages after viewing televised violence. Episode in which someone is reduced to tears, humiliated or simply made fearful (perhaps by threat of violence) are still violent. Violent is the adjective meaning, the situation whereby injury is caused by exhibiting intense emotional or mental excitement. So, the inherently different nature of televised violence becomes yet another variable. Television violence does not exist in isolation, so our understanding of what is violent behaviour is the formation of our attitudes towards violence and it happens through a collection and accumulation of experiences from various media and texts.

Toff and Sessions (2005) posited that violence is not a single act of a single text within a single medium. The underlying fact about violence (especially televised violence) is that the viewers form different reactions towards a given violence movie. Whereas so the viewers might exhibit non-aggressive attitudes; others might be aggressive after watching televised violent movies. (Leach \& Zekpe, 2010).

Sexual violence means a woman has been physically forced to have sexual intercourse, had sexual intercourse because she was afraid of what her partner might do, or was forced to do something sexual she found degrading or humiliating. Though recognized as a serious and pervasive problem, emotional violence does not yet have a widely accepted definition, but includes, for example, being humiliated or belittled and being scared or intimidated. Intimatepartner violence (also called "domestic" violence) means a woman has encountered any of the above types of violence at the hands of an intimate partner or ex-partner. This tends to be one of the most common and universal forms of violence experienced by women. In Nigeria, violence against women is a prevalent harm to peace and security because it undermines the basic rights, freedoms, health and welfare of women and national development. It occurs in many settings and at many hands, including those of relatives, acquaintances, employers, insurgents and the state.

Eamon (2005) observed that most forms of violence directed specifically against women in Nigeria seems to be met with silence not only by the state but also by much of the human rights community. Incidents of violence in Nigeria which negate peace and security include battery, beatings, torture, acid baths, rape, kidnapping, and even death through honor killings. It is estimated that one in every three women suffers domestic violence from the hands of those who claim to love and protect them (Hamm, 2000). However, many of the victims do not speak out about violations of their rights due to a lack of positive response from society. Hence, domestic violence is so entrenched in the society that even the victims condone such violations of their rights with some claiming it is a sign of love (East African Standard, 2001). Furthermore, due to poverty, fear and economic dependence on men, many victims suffer in silence for fear of losing the economic support of the male "perpetrator". Amnesty International (2005) thus observes that where a victim summons the courage to report to law enforcement agents, the issue 
is trivialized and termed a private matter. Thus, this study investigated factors responsible for violent behaviours among secondary school students expressed by teachers in the Ilorin metropolis.

\section{Problem}

A teacher has reasons to worry if his class is unresponsive and boring and if students seek satisfaction in rowdy behaviour or frequent day-dreaming. The source of trouble may be the curriculum. This means that the school program is organized in a way that it fails to meet the needs of many boys and girls who represent such great diversity in interests, abilities and backgrounds. It is notable that the secondary school curriculum has been academic and bookish and that learning has been based on the accumulated heritage as recorded in books with a singular neglect of the experiences and problems of everyday living. In secondary schools today, the problem of student adjustment to the curriculum is so acute. Sometimes the most important goal of education, that is, improved behaviour of boys and girls, has been neglected. Furthermore, Alcorn et al. observed that the teacher and the teaching methods that are monotonous with definite routines and inappropriate instructional procedures, lead to behaviour problems. Teachers may also be ineffective. The most frequently perceived causes of teacher ineffectiveness are deficiencies in components of pedagogical knowledge, in class components requiring student teacher interaction such as lesson implementation skills, the ability to establish rapport with students, and classroom management skills (Torff \& Sessions, 2005).

Promotional policies, particularly in exams, are also a source of discipline problems. Alcorn et al. (2000) noted that excessive stress on examinations or competition for school marks creates a climate conducive to behavioural problems. The welfare of either the individual or the group may be jeopardized. Brendgen et al. (2007) elaborated on the point that the teacher-child relationship exerts a major influence on children's academic, social, behavioural and emotional problems. Children who have a negative relationship with their teachers, especially those who experience verbal abuse by the teacher are likely to miss out on important learning opportunities and are at risk for an increase in behavioural problems. The teacher himself is one of the sources of behavioural problems in schools. It is advisable that teachers work in harmony with fellow teachers, the head teacher, and students. This will foster unity and create confidence among students with the adults leading them in the school.

Of all the influences in a school that provoke misbehavior or good behaviour on the part of students, the most pervasive is that of teachers. Personality, character, attitudes, and observable actions are all factors that determine the effectiveness of a teacher's relationships both with students and colleagues. The personality of the teacher is crucial. Those who demonstrate qualities of kindness, sympathy, and understanding radiate warmth among the students. Teachers in this respect are required to be professional in their way of doing their work (Amundson, 1988) Violence in secondary schools is a pertinent contemporary issue that requires urgent attention because of the damage it causes. It has led to deaths, destruction of school property, and disruption of teaching and learning, resulting to poor academic performance. This study, therefore, sought to discover factors responsible for violent behaviours among secondary school students expressed by teachers in the Ilorin metropolis. 


\section{Research Question}

- What are the factors responsible for violent behaviour among secondary school students as expressed by teachers in Ilorin Metropolis?

\section{Hypotheses}

The following hypotheses were postulated and tested for the study;

1. There is no significant difference in the factors responsible for violent behaviours among secondary school students as expressed by teachers in Ilorin Metropolis based on gender.

2. There is no significant difference in the factors responsible for violent behaviours among secondary school students as expressed by teachers in Ilorin Metropolis based on years in teaching.

\section{Methodology}

The descriptive survey method of research was adopted in this study. Stangor (2004) described descriptive survey as a systematic description of an event in a very factual and accurate manner. Daramola (2006) posited that the descriptive survey approach is the systematic attempt to describe characteristics of a given population or areas of interest factually. Thus, a descriptive survey type was suitable for this study and was carefully employed due to its advantages which helped the researcher collect data. This was also considered appropriate for this study because the researcher sought to find out the current situation with respect to the factors responsible for violent behaviour among secondary school students as expressed by teachers in the Ilorin metropolis.

The population for this study comprised all teachers in the Ilorin metropolis. A multistage sampling procedure was employed to select 216 teachers. At stage one, simple random sampling was used by the researchers to select eighteen secondary schools. At stage two, simple random sampling was used to select 12 teachers from each of the 18 schools selected, making a total of 216 teachers who represented the respondents for this study. A questionnaire tagged "Factors Responsible for Violent Behaviour Questionnaire (FRVBQ)" was used to gather data from the respondents.

\section{Validity of the Instrument}

One of the most important psychometric properties of research instrument is validity. Validity, according to Adegboyega (2018), is the extent to which an instrument measures what it 
purports to measure. To ensure that the instrument is content and face valid, the instrument was given to lecturers in the Faculty of Education, University of Ilorin. Their input, suggestions and corrections were taken into consideration when producing the final draft of the instrument.

\section{Reliability of the Instrument}

Reliability has to do with consistency and stability of an instrument to yield the same result at different time interval of administration. According to Adegboyega (2018), reliability is the consistency, accuracy, stability and trustworthiness of a measuring instrument, that is, how far the same instrument would give the same score on different occasions or with different sets of equipment items under the same condition. In order to establish the reliability of the questionnaire form, the test re-test method was used. The instrument was administered twice on an interval of four weeks to the same respondents. The scores from the two administrations were correlated using Pearson's Product Moment Correlation method. The coefficient derived was 0.82 which was accepted as being reliable for the study.

The data that was obtained was analyzed using percentages, mean and standard deviation as well as rank order for the descriptive data while t-test and Analysis of Variance (ANOVA) statistical analysis was used to test the null hypotheses generated. The t-test statistical method was used to compare means of two independent variables.

\section{Results}

\section{Demographic Data}

This section presents the results of data obtained from the respondents in percentages.

Table 1: Distribution of Respondents Based on Gender

\begin{tabular}{lcc}
\hline Gender & Frequency & Percentage \\
\hline Male & 33 & 15.28 \\
Female & 183 & 84.72 \\
Total & $\mathbf{2 1 6}$ & $\mathbf{1 0 0 . 0}$ \\
\hline
\end{tabular}

Table 1 indicates that $33(15.28 \%)$ of the respondents were males, while $183(84.72 \%)$ of the respondents were females. 
Table 2: Distribution of Respondents Based on Years in Teaching

\begin{tabular}{lcc}
\hline Years in teaching & Frequency & Percentage \\
\hline Below 10 years & 85 & 39.35 \\
11 years \& above & 131 & 60.65 \\
Total & $\mathbf{2 1 6}$ & $\mathbf{1 0 0 . 0}$ \\
\hline
\end{tabular}

Table 2 indicates that $85(39.35 \%)$ of the respondents have spent below 10 years in teaching, while $131(60.65 \%)$ of the respondents were have spent 11 years and above in teaching.

\section{Research Question}

What are the factors responsible for violent behaviours among secondary school students as expressed by teachers in the Ilorin Metropolis?

Table 3: Mean and Rank Order on the factors responsible for violent behaviours

\begin{tabular}{|c|c|c|c|}
\hline Item No. & $\begin{array}{l}\text { In my own opinion, the followingfactors are responsible for } \\
\text { violent behaviours }\end{array}$ & Mean & Rank \\
\hline 1 & extreme annoyance displayed by parents on children & 3.40 & $1^{\text {st }}$ \\
\hline 3 & extreme harshness towards children by parents & 3.36 & $2^{\text {nd }}$ \\
\hline 2 & inconsistent parent responses to children's needs & 3.27 & $3^{\text {rd }}$ \\
\hline 13 & derogatory languages used on other children & 3.25 & $4^{\text {th }}$ \\
\hline 20 & improper home training & 3.22 & $5^{\text {th }}$ \\
\hline 6 & $\begin{array}{l}\text { constant emphasis on children's wrong doings without praises } \\
\text { for good deeds }\end{array}$ & 3.20 & $6^{\text {th }}$ \\
\hline 5 & giving in to every of the child's demands & 3.18 & $7^{\text {th }}$ \\
\hline 14 & bullying tendencies inherited from either parents & 3.17 & $8^{\text {th }}$ \\
\hline 11 & fighting engaged in by parents & 3.17 & $8^{\text {th }}$ \\
\hline 17 & consistent abuse of the children & 3.16 & $10^{\text {th }}$ \\
\hline 10 & the ways parent assist children to deal with daily frustrations & 3.15 & $11^{\text {th }}$ \\
\hline 16 & frustrating children's personal decisions & 3.14 & $12^{\text {th }}$ \\
\hline 9 & freedom to openly discuss children's feelings & 3.14 & $12^{\text {th }}$ \\
\hline
\end{tabular}




\begin{tabular}{llll}
\hline 12 & inability of parents to satisfy children's pressing needs & 3.13 & $14^{\text {th }}$ \\
4 & too much freedom for children & 3.11 & $15^{\text {th }}$ \\
8 & encouraging children to be impulsive against other children & 3.08 & $16^{\text {th }}$ \\
18 & open arguments with the children & 3.05 & $17^{\text {th }}$ \\
15 & exposing children to violent movies & 3.02 & $18^{\text {th }}$ \\
19 & negative emotional responses of family members & 2.98 & $19^{\text {th }}$ \\
7 & obvious neglect & 2.95 & $20^{\text {th }}$ \\
\hline
\end{tabular}

Table 3 presents the mean and rank order of the respondents' view of factors responsible for violent behaviours. The table indicates that the item which states that factors responsible for violent behaviours through "extreme annoyance displayed by parents on children", ranked 1st with a mean score of 3.40. Item 3 which states that "extreme harshness towards children by parents" ranked 2nd with a mean score of 3.36. Ranked 3rd is item 2 with a mean score of 3.27 and states that "inconsistent parent responses to children's needs". On the other hands, item 15 which states that factors responsible for violent behaviours through "exposing children to violent movies" ranked 18th with a mean score of 3.02. Item 19 which states that "negative emotional responses of family members" ranked 19th with a mean score of 2.98 , while item 7 which states that "obvious neglect" ranked 20th with a mean score of 2.95 .

\section{Hypotheses Testing}

Two null hypotheses were generated and as well tested for this study. The hypotheses were tested using t-test statistical method at 0.05 level of significance.

Hypothesis 1: There is no significant difference in the factors responsible for violent behaviours among secondary school students as expressed by teachers in the Ilorin Metropolis based on gender. 
Table 4: Means, Standard Deviations and t-value on the factors responsible for violent behaviours on the Basis of Gender

\begin{tabular}{lccccccc}
\hline Gender & $\mathbf{N}$ & Mean & SD & df & $\begin{array}{c}\text { Cal. } \\
\text { t-value }\end{array}$ & $\begin{array}{c}\text { Critical } \\
\text { t-value }\end{array}$ & p-value \\
\hline Male & 33 & 61.50 & 3.54 & & & & \\
Female & 183 & 61.96 & 7.10 & & & 1.96 & 0.69 \\
\hline
\end{tabular}

Table 4 shows a calculated t-value of 0.39 , critical t-value of 1.96 and a p-value of 0.69 . Since the calculated p-value of 0.69 is greater than the alpha p-value at 0.05 , the hypothesis is not rejected. Hence, there is no significant difference in the factors responsible for violent behaviours among secondary school students as expressed by teachers in Ilorin Metropolis based on gender.

Hypothesis 2: There is no significant difference in the factors responsible for violent behaviours among secondary school students as expressed by teachers in the Ilorin Metropolis based on years in teaching.

Table 5: Means, Standard Deviations and t-value on the factors responsible for violent behaviours based on years in teaching

\begin{tabular}{lccccccc}
\hline Years & $\mathbf{N}$ & Mean & SD & df & $\begin{array}{c}\text { Cal. } \\
\text { t-value }\end{array}$ & $\begin{array}{c}\text { Critical } \\
\text { t-value }\end{array}$ & p-value \\
\hline Below 10 years & 85 & 52.40 & 4.51 & 214 & 1.02 & 1.96 & 0.10 \\
11 years \& above & 131 & 54.07 & 6.83 & & & & \\
\hline
\end{tabular}

Table 5 shows a calculated t-value of 1.02 , critical t-value of 1.96 and a p-value of 0.10 . Since the calculated p-value of 0.10 is greater than the alpha p-value of 0.05 , the hypothesis is not rejected. Hence, there is no significant difference in the factors responsible for violent behaviours among secondary school students as expressed by teachers in the Ilorin metropolis on the basis of years in teaching. 


\section{Discussion}

The study revealed those factors responsible for violent behaviours among secondary school students are extreme annoyance displayed by parents on children, extreme harshness towards children by parents, inconsistent parental responses to children's needs, derogatory languages used on other children and improper home training among others. These show that parental attitude and values influence bullying behaviours among in-school adolescents. It was supported by Eamon (2005) who posited that students who have imbibed bullying attitudes and behaviours lack ideal family upbringing and are able to manifest acts of misconduct in their immediate and distance environments.

According to the findings of Adegboyega (2019), parenting entails caring, protection, guidance, and provision of basic needs for a child's upkeep in order for him or her to be properly equipped to meet the challenges of life, in accordance with the laws of the land. In desperation, many parents have decided not to be responsible for their children's needs and aspirations.

Findings revealed that there was no significant difference in the factors responsible for violent behaviours among secondary school students as expressed by teachers in the Ilorin Metropolis on the basis of gender. This was supported by Eamon (2005), and Cheurprakobkit and Barstch (2005) in their separate study which revealed that mothers who are more educated and who delay child bearing have been shown to provide a more cognitively stimulating and supportive environment at home which has a positive effect on child behaviour.

Findings also revealed that there was no significant difference in the factors responsible for violent behaviours among secondary school students as expressed by teachers in the Ilorin Metropolis on the basis of years in teaching. This was corroborated by Odebumi (2005) who stressed that parents are made aware of favourable environments for children who may be academically prepared for formal school based on their level of education primary, secondary school and tertiary institutions.

\section{Conclusion}

The study revealed that the factors responsible for violent behaviours through extreme annoyance displayed by parents on children, extreme harshness towards children by parents, inconsistent parent responses to children's needs, derogatory languages used on other children, and improper home training among others. There were no significant differences in the factors responsible for violent behaviours among secondary school students as expressed by teachers in Ilorin metropolis based on gender and years in teaching.

\section{Recommendations}

Based on the findings of this study, it was recommended that:

- Counselling centres should be established and made functional in all secondary schools in Ilorin and Nigeria in general. 
- Professional Counselling Associations should organize seminars and workshops with sub-themes covering some of the variables on culture and personality development of inschool adolescents.

- A seminar, conference or workshop should be created where counsellors and school administrators could be invited to the conference and presentations could be made on how the socio-emotional development of different people and races/zones influences the personalities of the students and people in general. 


\section{References}

Adegboyega, L. O. (2018). Influence of achievement motivation on Nigerian undergraduates' attitude towards examination. International Journal of Instruction, 11(1), 77-88.

Adegboyega, L. O. (2019). Single parenting and emotional development of primary school students as viewed by Nigerian primary school teachers. Mimbar Sekolah Dasar, 6(1), 116-125.

Alcorn, D.M., Kinder, S.J., \&Schunert, R.J. (2000). Better teaching in secondary schools (3 rd ed.). New York: Holt, Rinehart and Winston Inc.

Amundson, K. (1988). Challenges for school leaders. Arlington, Virginia: American Association of School Administrators.

Brendgen, M., Vitaro, F., Tremblay, E.R., \& Bukowski, M. W. (2007). Verbal abuse by the teacher during childhood and academic, behavioural and emotional adjustment in young adulthood. Educational Psychology, 99(1), 26-38.

Cheurprakobkit, S., \& Barstch, A.R. (2005). Security measures on school crime in Texas middle and high schools. Educational Research, 47(2), June. Abingdon: Routledge Publishers.

Daramola, S. O. (2006). Research and statistical methods in education. Ilorin: Bamitex Printing and Publishing Company.

Eamon, M. K. (2005). Social-demographic, school, neighborhood, and parenting influences on academic achievement of Latino young adolescents. Journal of Youth and Adolescence, 34(2), 163-175.

East African Standard (2001, July 1). School unrest. East African Standard, p. 1. Nairobi: SG.

English, W. F. (2004). The sage handbook of educational leadership: Advances in theory, research and practice. London: Sage Publications.

Hamm, J. V. (2000). Do birds of a feather flock together? Individual, relationship, and contextual bases for African American, Asian American, and White adolescents' selection of similar friends. Developmental Psychology, 36, 209-219.

Leach, L., \& Zepke, N. (2010). Making it into the pipeline: Transitions from school to tertiary education. Adult Learning in Aotearoa New Zealand, 38(1), 5-22.

Macionis, J.J. (2007). Sociology (6 ${ }^{\text {th }}$ ed.). New Jersey: Prentice-Hall. 
Nation Team (2007, March 27). Schools to tighten transfer rules.Daily Nation. Nairobi: Nation Media Group Ltd.

Pepler, D. J. \& Craig, W. M. (2000). Victims turn aggressors: Factors in the development, making a difference, recognizing and preventing bullying. National Resource Centre for safe schools.

Rukundo, A., Kibanja, G., \& Steffens, K. (2017). Factors influencing psychoactive substance use among adolescents in public secondary schools in Uganda. The International Journal of Alcohol and Drug Research, 6(1), 69-76. https://doi.org/10.7895/ijadr.v6i1.237

Rutebuka, K.A. (2001). School violence and unspoken messages to children: The remedy is in your hands. Michigan: Bash Books.

Severe, S. (2000). How to behave so your children will, too. New York: Penguin Books.

Schuster, J. M. (1996). The performance of performance indicators in the arts. Non profit Management \& Leadership, 7(3), 253-269.

Stangor, C. (2004). Social groups in action and interaction. New York: Psychology Press.

Torff, B., \& Sessions, D. N. (2005). Principals' perceptions of the causes of teacher ineffectiveness. Journal of Education Psychology, 97(4), Washington D.C: American Psychological Association. 